\title{
USP and Dissolution-20 Years of Progress
}

William E. Brown and Margareth R. Marques*

e-mail:MRM@usp.org

U. S. Pharmacopeia, Rockville, MD, USA

U SP has been an important proponent of dissolution testing since the late 1960s when a USP and NF joint panel on physiological availability decided on dissolution as a test and described the apparatus that would be used. From an initial set of 12 product dissolution tests in the USP and the NF in 1970, the number of tests for immediate- as well as modified-release products has grown continually. By 1995, there were more than 470 monographs with dissolution tests. Today, USP 37 has over 750 monographs with dissolution tests. The number of modified-release product monographs with dissolution tests has grown from 23 in 1995 to 87 in 1994. At that time, four extended-release and three immediate-release monographs had multiple dissolution tests; today most of the modified-release monographs have multiple tests. Additionally in 1995, there were drug release pattern tests for one ocular system and one intrauterine contraceptive system. In addition to those two monographs, today there are three additional monographs representing transdermal systems with drug release tests. The first monograph for periodontal systems (Minocycline Periodontal System) became official in the Second Supplement of USP 32NF 27 on Dec 1, 2009, and this monograph has a dissolution test using rotator tubes and an acceptance criterion where the amount of drug dissolved decreases with time. The first USP monograph with a dissolution test using USP Apparatus 4 (flow-through cell), Rufinamide Tablets, became official in USP 36-NF 31 on May 1, 2013. The progress of the major USP dissolution initiatives over the last 20 years is recounted below.

\section{<724> DRUG RELEASE}

The USP General Chapter $<724>$ Drug Release became official in USP XXI-NF XVI on Jan 1, 1985. At that time, the chapter stated the procedures for extended-release and enteric-coated dosage forms using only USP Apparatus 1 and 2. A major revision to this chapter was published in the Eighth Supplement of USP XXI-NF XVI (official on Nov 15,1988 ) with the inclusion of a section for transdermal delivery systems. This revision introduced the paddleover-disk apparatus, the cylinder, and the reciprocating disk in the drug release testing of transdermal systems. With the later addition of USP Apparatus 3 (reciprocating cylinder) and Apparatus 4 (flow-through cell), the other apparatus were renumbered to Apparatus 5 (paddle over

*Corresponding author. disk), Apparatus 6 (cylinder), Apparatus 7 (reciprocating disk).

With the harmonization of General Chapter $<711>$ Dissolution between the United States Pharmacopeia and the European and Japanese Pharmacopoeias, USP Apparatus 3 and Apparatus 4 were transferred to $\langle 711\rangle$, and USP Apparatus 5, 6, and 7 remained under $\langle 724\rangle$. Chapter $\langle 724\rangle$ is not harmonized among the three pharmacopeias.

Modernization of $<724>$ was published in Pharmacopeial Forum 39(4) where the entire text was rewritten to facilitate finding the information and making any future revisions to the chapter. In addition, the apparatus drawings and specifications were updated, and new options on how to attach the transdermal system to the apparatus were included. This revision was published in the Second Supplement to USP 37-NF 32, and it will be official on Dec 1, 2014.

\section{PERFORMANCE VERIFICATION TESTING}

From the 1970s, USP worked closely with PMA and its successor association, PhRMA, to control the variability of results due to the apparatus and assembly using the calibrator paradigm. The ranges for what was then known as calibration were set using a statistical analysis of the results returned by collaborative study participants (1-3). Originally, two tablet products, a disintegrating $50-\mathrm{mg}$ prednisone tablet and a non-disintegrating 300-mg salicylic acid tablet, were used for the basket and paddle apparatus. With the introduction of the reciprocating basket, two additional reference materials, theophylline extended-release granules and chlorpheniramine maleate extended-release tablets, were added as calibrators for that apparatus (4).

Changes in the approach to performance verification testing have been notable over the last 20 years. In 1995, Richard F. Lindauer, director of the USP Drug Research and Testing Laboratory, questioned the value of the testing scheme comprising eight tests-two apparatus, two conditions, two reference materials (5). This was followed by a recommendation from the Dissolution Test Working Group of PhRMA to reduce the number of test conditions (6). Elimination of the use of salicylic acid tablets, enhanced mechanical calibration, and the introduction of a new 10-mg prednisone tablet for use with baskets and paddles was recommended as the result of an industry study (7). The number of conditions for both Salicylic Acid Tablets RS and Prednisone Tablets RS was halved to a total of four in 2001. Salicylic acid tablets were removed from 
the testing requirements in the USP dissolution chapter in 2009.

A new formulation with $10 \mathrm{mg}$ prednisone in a disintegrating tablet, which replaced the longstanding 50-mg prednisone tablet, was introduced in 1999. This product reproduced the FDA NCDA \#2 tablets that were the subject of numerous articles published in Pharmacopeial Forum (8-12). This tablet served as the platform for USP to introduce a new approach to the performance verification test in 2007 (13).

\section{POOLED DISSOLUTION}

USP explored the opportunity to reduce dissolution testing burden and waste generation by the analysis of pooled dissolution samples. The concept was proposed as a change to both the USP dissolution chapter and monographs for selected products (14). Comments were received and responses offered (15). Comparison of the criteria for pooled and traditional procedures was offered (16). The initial list of 272 monographs considered for pooled sampling was published in PF 21(1) but was reduced to proposals in 70 monographs in PF 22(5), 1996, after comments were received. Currently, there are 66 USP monographs where pooled dissolution is part of a dissolution procedure. USP General Chapter <2040> Disintegration and Dissolution of Dietary Supplements uses a pooled sample approach.

\section{HARMONIZATION}

In 1995 a joint report of the Section for Official Laboratories and Medicines Control Services and the Section of Industrial Pharmacists of the International Pharmaceutical Federation (FIP) was published in Pharmacopeial Forum (17) giving guidelines for dissolution testing of solid oral products. This joint report recommended harmonization of dissolution procedures and criteria across the pharmacopoeias and national and international regulators. The harmonization policies of the Pharmacopeial Discussion Group (PDG) were presented in the same issue of PF. The process of harmonizing the dissolution chapters among the PDG involved lengthy discussions over a number of years. The harmonized dissolution chapter in USP was made official on April 1, 2006, in USP 29. USP agreed not to unilaterally revise the harmonized text. National text particular to USP is allowed within a harmonized chapter. USP national text includes pooled sampling and the performance verification test. A change to the description of the wire mesh used in basket construction was added as a revision to the harmonized document and published in USP 34 in 2011.

\section{MULTIPLE DISSOLUTION, DISINTEGRATION, OR DRUG RELEASE TESTS}

Typically, a USP monograph for dosage forms may have multiple dissolution, disintegration, or drug release tests when the product is a modified-release dosage form (ex- tended- or delayed-release) or, in the case of immediate release, the active ingredient is poorly soluble in aqueous solvents. In any of these cases, the dissolution, disintegration, or drug release test may be formulation dependent.

In 1996 the FDA and the USP Dissolution, Bioequivalence, and Bioavailability Subcommittee developed a mechanism to address multiple release tests in a compendial monograph (18). Initially, this mechanism was developed only for extended-release dosage forms but later was extended to all dosage form monographs that may have multiple dissolution tests. In the case of multiple dissolution tests, the USP monograph will have a labeling requirement that states "when more than one dissolution, disintegration or drug release test is given, the labeling states the Dissolution, Disintegration or Drug Release test used only if Test 1 is not used." Most companies display this information in the leaflet or insert that goes in the product packaging. This labeling statement is valid only for products marketed in the United States. For other countries, the appropriate regulatory body needs to be contacted.

The multiple tests are numbered in the order in which they were approved by the appropriate USP expert committee. Consequently, Test 1 is not necessarily the test used by the Reference Listed Drug product.

The fact that a USP monograph has multiple release tests does not imply that all the products meeting the requirements stated in the monograph are bioequivalent or interchangeable. FDA decisions on bioequivalence and interchangeability can be checked in the Orange Book at http://www.accessdata.fda.gov/scripts/cder/ob/default. cfm.

\section{SIMULATED INTESTINAL MEDIUM}

A change to the $\mathrm{pH}$ of simulated intestinal fluid from the longstanding value of 7.5 to a $\mathrm{pH}$ of 6.8 as well as a reconsideration of the $\mathrm{pH}$ for dissolution media in a number of monograph tests were discussed in an article by Gray and Dressman (19). Dissolution media with a $\mathrm{pH}$ greater than 6.8 are now increasingly rare and reflect special cases.

\section{< 1090> IN VIVO BIOEQUIVALENCE GUIDANCES}

General Chapter <1090> In Vivo Bioequivalence Guidances as found in USP 23 (1995) provided general guidance on the conduct of bioequivalence tests as well as protocols for specific drugs. The general chapter reflected information provided by the Division of Bioequivalence of the FDA Office of Generic Drugs. Additional drug-specific protocols were added to the five from USP 23 as they became available. In the late 1990s, FDA discontinued individual drug product guidances in favor of a general guidance on bioequivalence and bioavailability. The USP general chapter content was revised in 2009, and the name of the chapter changed to Assessment of Drug Product Performance-Bioavailability, Bioequivalence, and Dissolution. The chapter now serves as a source of 
information as well as an index of the relevant FDA and WHO guidance documents. In addition to information on the conduct of bioavailability and bioequivalence studies, the revised content in USP 32 gives information on the uses for a dissolution procedure including support of biowaivers based on the Biopharmaceutics Classification System.

\section{$<1088>$ IN VITRO AND IN VIVO EVALUATION OF DOSAGE FORMS}

$<1088>$ In Vitro and In Vivo Evaluation of Dosage Forms was published in 1995 in USP 23. The chapter spoke to method development for dissolution testing of immediate- and modified-release dosage forms as well as the physicochemical, pharmacodynamic, and pharmacokinetic characterization of drug substances and drug products. Most importantly, the chapter spoke to the value and development of in vitro-in vivo correlations. Lewis J. Leeson (20) published an article in 2002 recommending an update to this chapter. The updated chapter, published in USP 35, is largely consistent with the revision in USP 23. The information on developing dissolution test procedures has been replaced with new information on developing in vitro-in vivo correlations including graphical representation of data analysis during the development of an IVIVC.

\section{<1092> THE DISSOLUTION PROCEDURE: DEVELOPMENT AND VALIDATION}

The concept for this new chapter was discussed in an article published in 2001 (21). The authors proposed that the chapter contain detailed information not only on the development of dissolution tests to supplement the information that was in $<1088>$ but also on the validation procedures particular to dissolution testing. Chapter <1092> The Dissolution Procedure: Development and Validation appeared in USP 29 in 2006. The review of the chapter was put on the work plan of the USP Dosage Forms Expert Committee for the 2010-2015 revision cycle. The committee has proposed a sweeping revision of the chapter in PF 40(1) 2014. The revision is discussed in an article in the same $P F(22)$.

\section{CAPSULES}

Certain types of capsules, depending on the composition of the capsule shell and the filling, may require dissolution conditions not covered by the USP General Chapters $\langle 711\rangle,<724>$, and $<1092>$. To start the discussion of the issues associated with dissolution testing of capsules, a paper was published in Pharmacopeial Forum (23). This paper gives an overview of the history, composition, and characteristics of the gelatin shell and the manufacturing and dissolution testing of liquid-filled capsules. The information in this paper was used to develop a new USP General Chapter <1094> Liquid-filled Capsules-Dissolution Testing and Quality Attributes that was published in
PF 38(1) [Jan-Feb 2012]. The comments received stated that this chapter could be more useful if it covered all types of capsules and not just the liquid-filled ones. The chapter was completely revised, its title was changed to <1094> Capsules-Dissolution Testing and Related Quality Attributes, and this new version was published in PF 39(3) [May-June 2013]. The chapter became official in the First Supplement to USP 37-NF 32 on Aug 1, 2014. The chapter discusses all types of capsules including dietary supplements, manufacturing, packaging, cross-linking in gelatin, critical quality attributes, and makes recommendations on how to develop and validate dissolution tests for this type of dosage form. With the changes made in $<711>$ Dissolution, Chapter <1094> will be revised to give additional information for the cases where the dissolution medium contains surfactants or other compounds that may denature the enzyme used and how to validate this procedure.

\section{USE OF ENZYMES IN THE DISSOLUTION TESTING OF GELATIN CAPSULES OR GELATIN-COATED TABLETS}

The current text in the General Chapter $<711>$ Dissolution allows the addition of enzymes to the dissolution medium when hard or soft gelatin capsules and gelatin-coated tablets do not conform to the dissolution specification. The text does not explicitly mention that the failure is due to the presence of cross-linking in the gelatin. If the gelatin capsule ruptures and the capsule contents are released into the dissolution medium but the capsule fails the dissolution test, the addition of enzymes to the dissolution medium is probably not going to improve the results. The chapter recommends the use of pepsin when the dissolution medium is water or has a $\mathrm{pH}$ less than 6.8 , but pepsin has good proteolytic activity to $\mathrm{pH} 4$. The chapter does not address this issue, and there are no enzymes recommended for the $\mathrm{pH}$ range of 4-6.8. Also, the chapter does not give any recommendations for a procedure to be used when the dissolution medium contains surfactants or other compounds that may denature the enzyme.

To address all these issues, Chapter $<711\rangle$ is being revised. The proposal will be available on November 1, 2014, in Pharmacopeial Forum 40(6) [Nov-Dec 2014], available free of charge at www.usppf.com. All comments and suggestions should be sent to Margareth Marques at MRM@ usp.org no later than Jan 31, 2015.

\section{REFERENCES}

1. PhRMA Quality Assurance Section Dissolution Committee. The USP Dissolution Calibrator Tablet Collaborative Study-An Overview of the 1994 Process. Pharm. Forum 1994, 20 (5), 8177-8201.

2. PhRMA Quality Assurance Section Dissolution Committee. The USP Dissolution Calibrator Tablet Collaborative Study-An Overview of the Fourth Quarter 1994 Process. Pharm. Forum 1995, 21 (3), 841-858. 
3. Pharmaceutical Research and Manufacturers of America. The USP Dissolution Calibrator Tablet Collaborative Study-An Overview of the 1996 Process. Pharm. Forum 1997, 23 (3), 4198-4237.

4. Gray, V. A. Drug Release Calibrators for Apparatus 3Collaborative Study Results. Pharm. Forum 1994, 20 (1), 6934-6943.

5. Lindauer, R. L. USP Dissolution Calibrator Tablets-Is It Time to Reduce the Amount of Testing Required to Calibrate Apparatus 1 and 2? Pharm. Forum 1995, 21 (5), 1397-1402.

6. Dissolution Test Working Group of Pharmaceutical Research and Manufacturers of America. USP dissolution calibrator tablets-Recommendations for reduced dissolution calibration testing. Pharm. Forum 1997, 23 (3).

7. Subcommittee on Dissolution Calibration, Pharmaceutical Research and Manufacturers of America (PhRMA). Dissolution Calibration: Recommendations for Reduced Chemical Testing and Enhanced Mechanical Calibration. Pharm. Forum 2000, 26 (4), 1149-1151.

8. Hamilton, J. F.; Moore, T. W.; Kerner, C. M. Reproducibility of Dissolution Test Results. Pharm. Forum 1995, 21 (5), 1383-1386.

9. Moore, T. W.; Hamilton, J. F.; Kerner, C. M. Dissolution Testing: Limitations of the USP Prednisone and Salicylic Acid Calibrator Tablets. Pharm. Forum 1995, 21 (5), 1387-1396.

10. Moore, T. W.; Shangraw, R. F.; Habib, Y. Dissolution Calibrator Tablets: A Recommendation for New Calibrator Tablets to Replace Both Current USP Calibrator Tablets. Pharm. Forum 1996, 22 (3), 24232428.

11. Moore, T. W.; Cox, D. C. Dissolution Testing: Collaborative Study of the In-house NCDA\#2 Dissolution Calibrator Tablets with USP Apparatus 2. Pharm. Forum 1997, 23 (3), 4250-4255.

12. Moore, T. W.; Cox, D. C.; Demarest, D. A. Dissolution Calibrator Tablets: A Scaled-up Lot of a New Calibrator Tablet Recommended to Replace Both Current USP Calibrator Tablets. Pharm. Forum 1997, 23 (6), 53525363.
13. Hauck, W. W.; Manning, R. G.; Cecil, T. L.; Brown, W.; Williams, R. L. Proposed Change to Acceptance Criteria for Dissolution Performance Verification Testing. Pharm. Forum 2007, 33 (3), 574-579.

14. Grady, L. T. Call for a Third Generation of Dissolution Testing and Principles of Application-An Initial Initiative Based on Recognition of Dissolution as a Batch Characteristic. Pharm. Forum 1995, 21 (1), 177.

15. Foster, T. S.; Gray, V. A. USP Dissolution $<711>$, Pooled Sampling-Response to Comments Received. Pharm. Forum 1997, 23 (3), 4248-4249.

16. Wojcik, R. C.; Zimmermann, A. G.; Utter, M. L.; Cundell, A. M. An Evaluation of the Dissolution Test Acceptance Sampling Procedure for Pooled Samples. Pharm. Forum 1995, 21 (4), 1169.

17. Section for Official Laboratories and Medicines Control Services and the Section of Industrial Pharmacists of the International Pharmaceutical Federation (FIP). FIP Guidelines for Dissolution Testing of Solid Oral Products Final Draft 1995. Pharm. Forum 1995, 21 (5), 1371-1382.

18. Gray, V. A.; Rippere, R. A. Labeling Issues for Recently Approved Abbreviated New Drug Applications for Extended-Release Products. Pharm. Forum 1996, 22 (1), 1942.

19. Gray, V. A.; Dressman, J. B. Change of pH Requirements for Simulated Intestinal Fluid TS. Pharm. Forum 1996, 22 (1), 1943-1945.

20. Leeson, L. J. In Vitro-In Vivo Correlations. Pharm. Forum [Online] 2002, 28 (4).

21. Gray, V. A.; Brown, C. K.; Dressman, J. B.; Leeson, L. J. Stimuli to the Revision Process. A New General Chapter on Dissolution. Pharm. Forum 2001, 27 (6), 3432-3439.

22. Skwierczynski, R.; Curry, P.; Gray, V.; Krämer, J.; Stippler, E.; Suggett, J.; Mirza, T.; Brown, W. Revision of the Dissolution Procedure: Development and Validation <1092>. Pharm. Forum [Online] 2014, 40 (1).

23. Marques, M.; Cole, E.; Kruep, D.; Gray, V.; Murachnian, D.; Brown, W.; Giancaspro, G. Liquid-filled Gelatin Capsules. Pharm. Forum 2009, 34 (4), 1029-1041. 